\title{
Microscopic and Macroscopic Physics of Earthquakes
}

\author{
Hiroo Kanamori and Thomas H. Heaton \\ Seismological Laboratory, California Institute of Technology, Pasadena California 91125
}

Frictional melting and fluid pressurization can play a key role in rupture dynamics of large earthquakes. For faulting under frictional stress $\sigma_{f}$, the temperature increases with $\sigma_{f}$ and the earthquake magnitude, $M_{W}$. If the thickness of the heated zone, $w$, is of the order of a few $\mathrm{mm}$, then, even for a modest $\sigma_{f}$, the temperature rise, $\Delta T$, would exceed $1000^{\circ}$ for earthquakes with $M_{W}=5$ to 6 , and melting is likely to occur, and reduce friction during faulting. If fluid exists in a fault zone, a modest $\Delta T$ of 100 to $200^{\circ}$ would likely increase the pore pressure enough to significantly reduce friction for earthquakes with $M_{W}=3$ to 4 . The microscopic state of stress can be tied to macroscopic seismic parameters such as the seismic moment, $M_{0}$, and the radiated energy, $E_{R}$, by averaging the stresses in the microscopic states. Since the thermal process is important only for large earthquakes, the dynamics of small and large earthquakes can be very different. This difference is reflected in the observed relation between the scaled energy $\tilde{e}=E_{R} / M_{0}$ and $M_{W}$. The observed $\tilde{e}$ for large earthquakes is 10 to 100 times larger than for small earthquakes. Mature fault zones such as the San Andreas are at relatively moderate stress levels, but the stress in the plate interior can be high. Once slip exceeds a threshold, runaway rupture could occur, and could explain the anomalous magnitude-frequency relationship observed for some mature faults. The thermally controlled slip mechanism would produce a non-linear behavior, and under certain circumstances, the slip behavior at the same location may vary from event to event. Also, slip velocity during a large earthquake could be faster than what one would extrapolate from smaller earthquakes.

\section{INTRODUCTION}

Modern broad-band seismic data have allowed seismologists to determine important seismic source parameters such as seismic moment, $M_{0}$, radiated energy, $E_{R}$, rupture parameters, and stress drops of earthquakes over a large magnitude range. However, at short length scales,

GeoComplexity and the Physics of Earthquakes

Geophysical Monograph 120

Copyright 2000 by the American Geophysical Union resolution of seismic methods is limited because of the complex propagation and wave attenuation effects near the Earth's surface, and it is difficult to determine the details of rupture process below some length scale. The complex wave forms at high frequency must be controlled by microscopic processes on a fault plane. Such microscopic processes include frictional melting [Jeffreys, 1942; McKenzie and Brune, 1972; Richards, 1977; Sibson, 1977; Cardwell et al., 1978], fluid pressurization [Sibson, 1973; Lachenbruch, 1980; Mase and Smith, 1985, 1987], acoustic fluidization [Melosh, 1979, 1996], dynamic unloading effects [Schallamach, 1971; Brune et al., 1993; Weertman, 1980; Ben-Zion and Andrews, 1998; Mora and Place, 1998, 1999] and geometrical effects [Scott, 1996]. 
The importance of thermal processes in earthquake mechanics has long been recognized. Sibson [1977] discussed the implication of frictional heating for fault dynamics. He suggested that melt formation and transient increases in fluid pressure caused by frictional heating may decrease the friction to near-zero values once slip is initiated. Here, we extend the model discussed by Sibson in light of recent seismological data. A recent study of the deep Bolivian earthquake $(M=8.3$, depth=637 km) [Kanamori et al., 1998] presented an interesting observational case which suggests a dominant role of thermal processes during faulting. For this earthquake, the released potential energy, $1.4 \times 10^{18} \mathrm{~J}$, is at least 30 times larger than the radiated energy, with a large amount of nonradiated energy (comparable to the total thermal energy released during the 1980 Mount St. Helens eruption) deposited in a relatively small fault zone over a time scale of less than a minute.

The thermal process during faulting would cause a complex sequence of events including local melting, freezing, fluid pressurization, micro-fracturing and injection of fluids. Although these microscopic processes are important for understanding rupture dynamics, it is difficult to determine how these processes work in detail during faulting because of the limited resolution of seismic methods.

In this paper, we investigate the effects of frictional melting and fluid pressurization and relate them to macroscopic seismic source parameters such as $M_{0}$ and $E_{R}$. This approach is somewhat similar to that of statistical mechanics in which the physics applied to small-scale processes is used to determine the average macroscopic parameters such as pressure and temperature.

\section{THERMAL BUDGET DURING FAULTING}

The possibility of frictional melting during faulting has been suggested by several investigators. In particular, McKenzie and Brune [1972] quantitatively investigated this problem as a one-dimensional heat conduction problem. They assumed that the fault surface is simultaneously heated during slippage (i.e. infinite rupture speed) over a finite time, and concluded that if both the frictional and driving stresses are of the order of $1 \mathrm{kbar}$, melting can occur for fault slips as small as one millimeter. Richards [1977] solved elasto-dynamic equations for a propagating elliptical crack, estimated frictional heating rate behind the rupture front, and showed that if the driving stress is 100 bars and the fault particle velocity is $10 \mathrm{~cm} / \mathrm{sec}$ at nucleation, a temperature rise of about $1000^{\circ}$ can occur within a few seconds. These studies indicate that frictional melting is likely to occur during seismic faulting, at least locally.

Here we consider a gross thermal budget during faulting under a frictional stress $\sigma_{f}$. Let $S$ and $D$ be the fault area

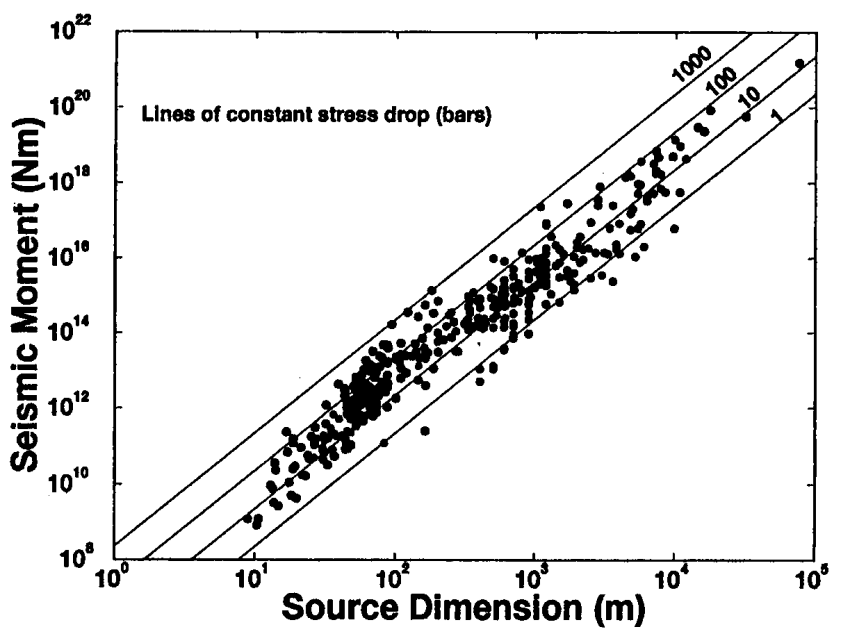

Figure 1. Static stress drop of earthquakes. Modified from [Abercrombie and Leary, 1993].

and the displacement offset respectively. Then the total heat generated during faulting is $Q=\sigma_{f} D S$. If we assume that the heat is distributed during seismic faulting within a layer of thickness $w$ around the rupture plane, the average temperature rise $\Delta T$ is given by

$$
\Delta T=Q / C \rho S w=\sigma_{f} D / C \rho w
$$

where $C$ is the specific heat, and $\rho$ is the density. In general $D$ increases with the earthquake magnitude, $M_{W}$. Here we use a simple circular model in which the static stress drop is $\Delta \sigma_{s}[$ Eshelby, 1957]. Then,

$$
D=(16 / 7)^{2 / 3}(1 / \pi) M_{0}^{1 / 3} \Delta \sigma_{s}^{2 / 3} / \mu
$$

where $M_{0}$ is the seismic moment and $\mu$ is the rigidity. From (1) and (2), we obtain

$$
\Delta T=(16 / 7)^{2 / 3}(1 / \pi) \sigma_{f} \Delta \sigma_{s}^{2 / 3} M_{0}^{1 / 3} / \mu C \rho w
$$

The seismic moment $M_{0}$ is related to $M_{W}$ by

$$
\log M_{0}=1.5 M_{W}+9.1 \quad\left(M_{0} \text { in } \mathrm{Nm}\right)
$$

The static stress drop, $\Delta \sigma_{s}$, for most earthquakes is in the range of 10 to 100 bars, as shown in Figure 1 [Kanamori and Anderson, 1975, Hanks, 1977, Abercrombie and Leary, 1993]. However, higher stress drops have been reported for some earthquakes for which the source dimension was determined well [e.g. Kanamori et al., 1990; Wald, 1992]. Also, there is evidence that the stress drop can be locally very high (up to 25 kbar) around small asperities [Nadeau and Johnson, 1998]. Since the 

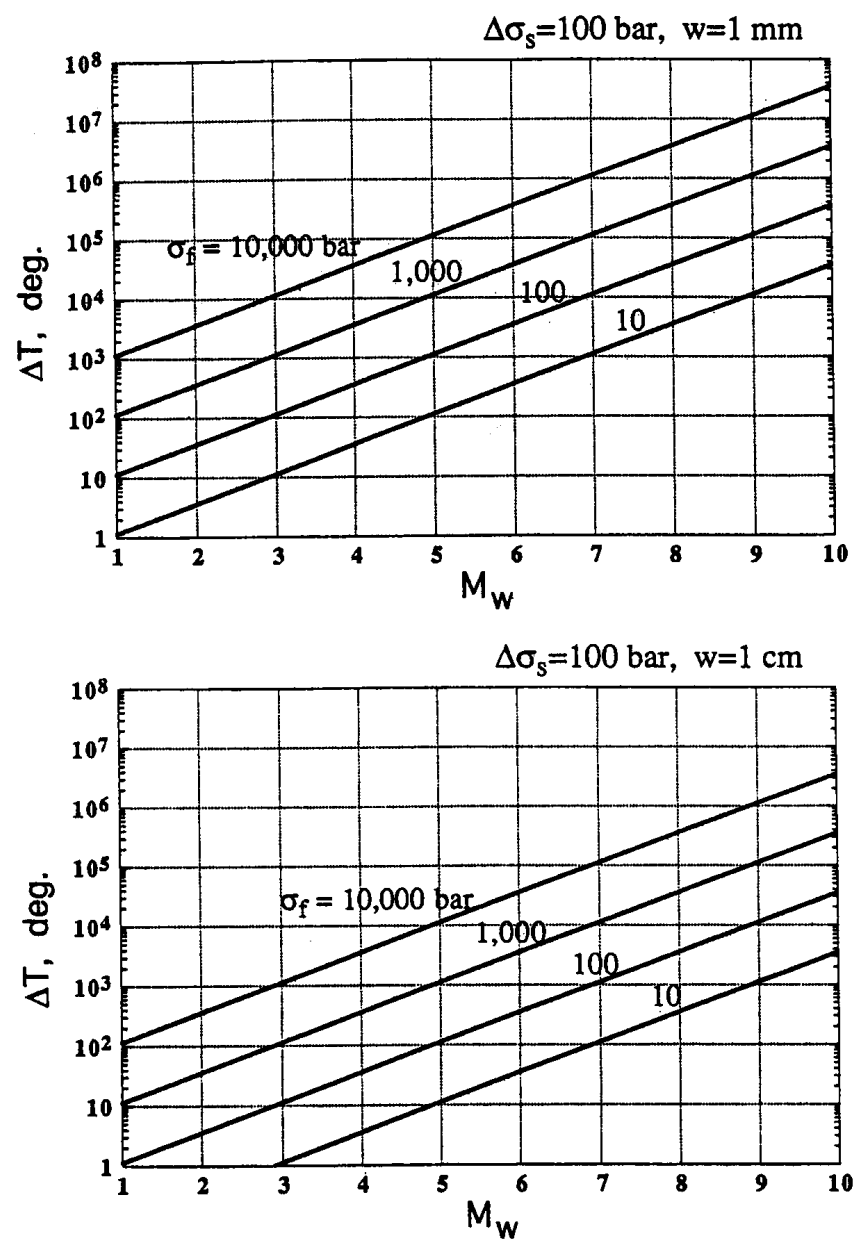

Figure 2. Temperature rise, $\Delta T$, in a fault zone as a function of magnitude, $M_{W}$, with the frictional stress, $\sigma_{f}$, as a parameter. The static stress drop $\Delta \sigma_{s}$ is assumed to be 100 bars.

The upper and lower figures correspond to the cases of $w$ (thickness of the heated zone) $=1 \mathrm{~mm}$ and $1 \mathrm{~cm}$, respectively.

thermal process considered here is most important at highstress spots, we use $\Delta \sigma_{s}=100$ bars and $\mu=0.3 \mathrm{Mbar}$ for estimation of $\Delta T$.

The thickness $w$ cannot be determined with seismological methods. Here, $w$ refers to the thickness of the coseismic slip zone, not the width of the shear zone along a fault. Fault surface breaks in bed rocks are often extremely sharp suggesting that the coseismic slip must have occurred in a very narrow zone. An example of a thin slip surface within a fault zone is described in Hubbert and Rubey [1959]. Laboratory studies by Goldsby and Tullis $[1998,1999]$ found that when the displacement is large, slip tends to be localized in a thin layer. Also, some pseudotachylytes layers are very thin, less than a millimeter [Otsuki, 1998], suggesting that the slip zone is thin at least locally.

It is true that wide shear zones are often found along a fault. Otsuki [1978] and Hull [1988] have shown that the width of the shear zone is about $1 \%$ of the total offset of the fault. Also, recent seismological studies suggest a 40 to $200 \mathrm{~m}$ thick zone with a low seismic velocity along several major faults [Li et al. 1994, 1997]. However, these wide fault-zone structures are probably formed by longterm processes involving deformation, chemical alteration, and aftershocks, and are not directly involved in coseismic slip.

If the slip zone is thin and heat is carried by thermal diffusion, then $w$ would be of the order of $\sqrt{k \tau_{0}}$, the thermal diffusion distance, where $k$ is the thermal diffusivity, and $\tau_{0}$ is the time scale of faulting. Since $\tau_{0}$ is less than $10 \mathrm{sec}$ for most seismic events, $w$ would be at most a few mm. A simple scaling shows that $D$ is proportional to the time scale of faulting, $\tau_{0}$, while $w$ is proportional to $\tau_{0}{ }^{1 / 2}$; then, we obtain from (1), $\Delta T \propto D^{1 / 2}$. This means that the thermal process would become increasingly important for large earthquakes.

Figure 2 shows $\Delta T$ calculated from (3) as a function of magnitude $M_{W}$ for two representative values of $w, 1 \mathrm{~mm}$ and $1 \mathrm{~cm}$. We used $C=1 \mathrm{~J} / \mathrm{g}^{\circ} \mathrm{C}$, and $\rho=2.6 \mathrm{~g} / \mathrm{cm}^{3}$. If $w=1$ mm, $\Delta T$ exceeds $1000{ }^{\circ} \mathrm{C}$ at $M_{W}=5$ even for a modest value of friction, $\sigma_{f}=100$ bars. Even for $w=1 \mathrm{~cm}, \Delta T$ exceeds $1000^{\circ} \mathrm{C}$ at $M_{W}=7$ for the same value of friction. If $\sigma_{f}>100$ bars, $\Delta T$ exceeds $1000{ }^{\circ} \mathrm{C}$ at a lower $M_{W}$. Thus, thermal process becomes important for large earthquakes.

Depending on whether fluid exists or not in a fault zone, two distinct thermal processes can happen. If there is no fluid in a fault zone, the temperature can rise to cause frictional melting. Figure 2 shows that if no fluid exists, frictional melting is likely to occur for earthquakes with $M_{W}=5$ to 7 . This general conclusion appears unavoidable even if the values of $\Delta \sigma_{s}, \sigma_{f}$, and $w$ used in (3) are varied over fairly large, but plausible, ranges.

Many investigators have found pseudotachylytes in cataclasites and presented them as evidence for frictional melting. Although pseudotachylytes are not commonly found [Sibson, 1975], the following are well-document examples. Lin [1994a, 1994b] reported on glassy pseudotachylytes from the Fuyun fault zone, China, which he believed to have been formed during seismic faulting at a minimum temperature of $1,450{ }^{\circ} \mathrm{C}$. Obata and Karato [1995] examined ultramafic pseudotachylytes from the Ivrea-Verbano zone, Italy, which are about $1 \mathrm{~cm}$ thick, and exhibit evidence for melting and cooling on a time scale of about $100 \mathrm{sec}$ or less under a differential stress of $3 \mathrm{kbar}$. Otsuki [1998] examined cataclasites from the Nojima fault, Japan, on which the 1995 Kobe earthquake occurred. According to Otsuki [1998], these cataclasites were not 
formed during the recent Kobe earthquake, but they were formed from granites at a depth of about $3 \mathrm{~km}$, and the original texture is exceptionally well preserved. They have a sandwich structure with alternating layers of pseudotachylytes (amorphous phase) and fine-grained rock. The pseudotachylyte layer, about 0.2 to $1 \mathrm{~mm}$ thick, exhibits evidence for melting at temperatures above 1,100 ${ }^{\circ} \mathrm{C}$ followed by rapid cooling.

Some pseudotachylytes are believed to be formed by crushing during faulting rather than melting [Lin et al., 1994; Lin, 1996]. It is also possible that pseudotachylytes were formed during faulting but they have been altered to clay minerals or crystallized into some kind of mylonites. We do not necessarily think that seismic faulting always causes melting. If a fault zone is highly crushed, the thermal energy can be distributed over a large volume and no melting occurs. Also, if fluid exists in a fault zone or some dynamic process such as acoustic fluidization or dynamic unloading occurs, the friction may drop before melting occurs. However, the existence of pseudotachylytes indicates that melting is an important process, at least locally, during faulting.

Melting does not necessarily mean reduction of friction. Once a thin melt layer is formed, high viscous friction may prevail depending on the thickness of the layer and the viscosity of the melt [Scholz, 1980]. In fact, Tsutsumi and Shimamoto [1997] performed high-velocity friction experiments and found a sharp increase in friction at the initiation of visible frictional melting. However, as shown by Spray [1993], the viscosity of molten pseudotachylytes is low and drops rapidly with the temperature so that friction is likely to drop eventually, though the details can be complex. Recent laboratory studies by Beeler et al. [1996] and Goldsby and Tullis [1998, 1999] demonstrated that friction dropped significantly when displacement was large. Goldsby and Tullis [1998, 1999] (details described in Tullis and Goldsby [1998]) found that, at a normal pressure of $1.12 \mathrm{kbar}$, the coefficient of friction dropped to 0.14 when a large displacement, $1.6 \mathrm{~m}$, occurred at a relatively high slip velocity of $3.2 \mathrm{~mm} / \mathrm{sec}$. These experiments were performed under confining pressure and the condition is close to that of natural earthquakes. From the observations of the sliding surface, they suggested that melting may have occurred during sliding.

Whether fluid exists in fault zones or not is still a materr of debate, but it is generally believed that some fault zones contain fluids and many mechanisms have been proposed to maintain high fluid pressure in fault zones [e.g. Irwine and Barnes, 1975; Byerlee, 1990; Rice, 1992]. If fluid exists in a fault zone, fluid pressurization could occur. This concept was introduced to seismology by Sibson [1973], and analyzed in great detail by Lachenbruch [1980], and Mase and Smith [1985, 1987]. Under the pressure-temperature conditions at the seismogenic depths, the thermal expansivity of water is of the order of $10^{-3}{ }^{\circ} \mathrm{C}$, and significant increase in pore pressure with temperature could occur. If fluid does not escape (small permeability) and the surrounding rock is not compressive, the pressure increase would be of the order of 10 bars $/ \mathrm{deg}$ [Lachenbruch, 1980]. In actual fault zones, permeability and compressibility vary and the pressure increase may be less. The most important parameter controlling the pressure change is the permeability. The analysis of Lachenbruch and Mase and Smith suggests that if permeability is less than $10^{-18} \mathrm{~m}^{2}$, fluid pressurization is most likely to occur with a temperature rise of less than $200{ }^{\circ} \mathrm{C}$, and friction will drop significantly. Permeability in the crust varies over a very wide range, more than a factor of $10^{10}$. Figure 3 shows the results for the samples taken from the Cajon drilling site in California [Morrow and Byerlee, 1992], and the Nojima fault, Japan [Ito et al., 1998]. Ito et al. [1998] show that permeability is very small near the middle of the shear zone, where the grain size of rocks is small. Ito et al.'s results are at a pressure of $500 \mathrm{bar}$ (corresponding to a depth of $1.5 \mathrm{~km}$ ), and suggest even smaller values in the deeper seismogenic zone. Although the distribution of permeability can be complex, these results suggest that pressure fluidization can play an important role, at least locally, in reducing friction. A modest $\Delta T$ of 100 to $200^{\circ}$ would likely increase the pore pressure enough to significantly reduce friction. Figure 2 shows that this can occur for earthquakes with $M_{W}=3$ to 5 . According to Chester and Chester [1998], the internal structure of the Punchbowl fault, California, implies that earthquake ruptures were not only confined to the ultracataclasite layer, but also largely localized to a thin prominent fracture surface. They suggest that mechanisms that are consistent with extreme localization of slip, such as thermal pressurization of pore fluids, are most compatible with their observations.

Since a fault zone is probably complex and heterogeneous in stress, fluid content, permeability, porosity, and compressibility, no single process is likely to dominate. In other words, we do not necessarily expect a single continuous layer of melting and pressurization; we envision, instead, a fault zone that consists of many microfaults (subfaults) where different mechanisms are responsible for slip at different stress levels, producing complex rupture patterns as observed.

\section{EARTHQUAKE ENERGY BUDGET}

We consider the energy budget for each subfault. The energy budget of earthquakes has been extensively studied by many investigators [e.g. Knopoff, 1958; Dahlen, 1977; Kostrov, 1974; Savage and Walsh; 1978]. Following these studies, and referring to Orowan [1960] and Savage and Wood [1971], here we consider a simple stress-release model. The simplest case is shown in Figure $4 \mathrm{a}$ which 


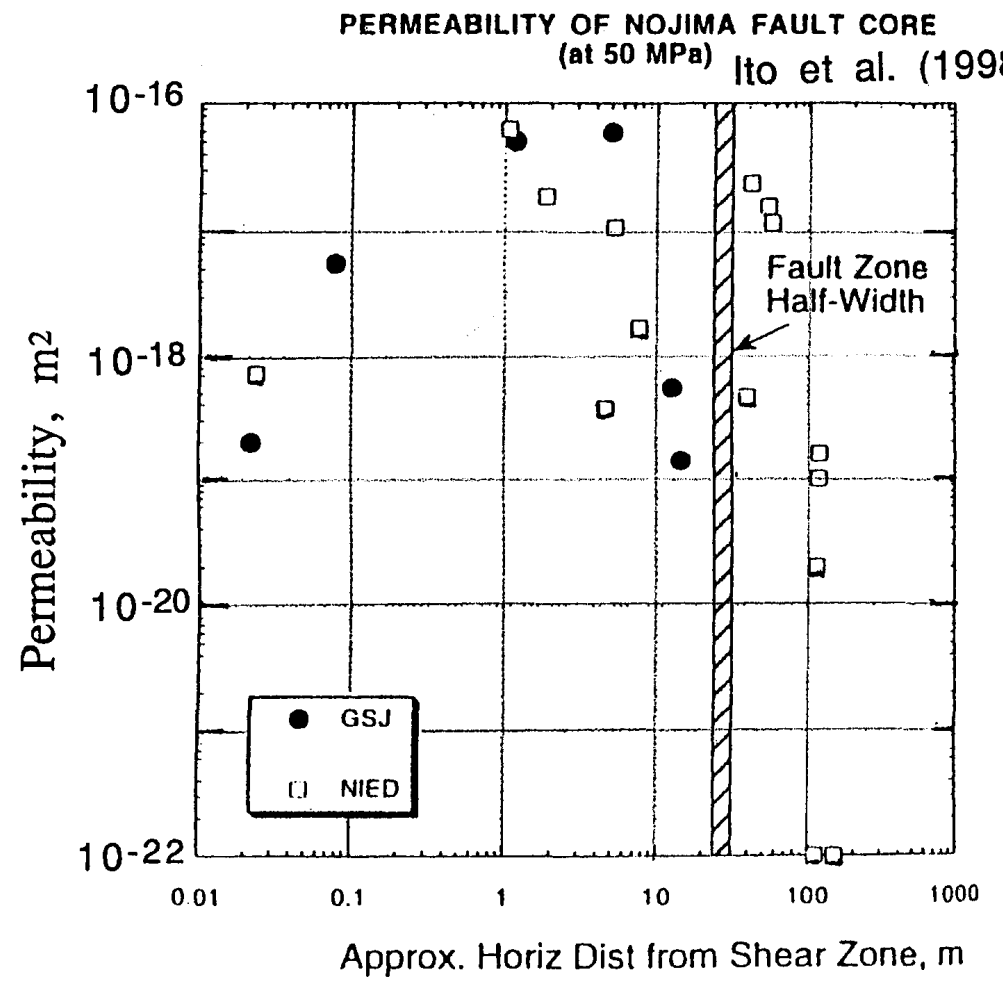

\section{Permeability of Cajon Pass Rocks \\ Morrow and Byerlee [1992]}

\section{Effective Stress, MPa}

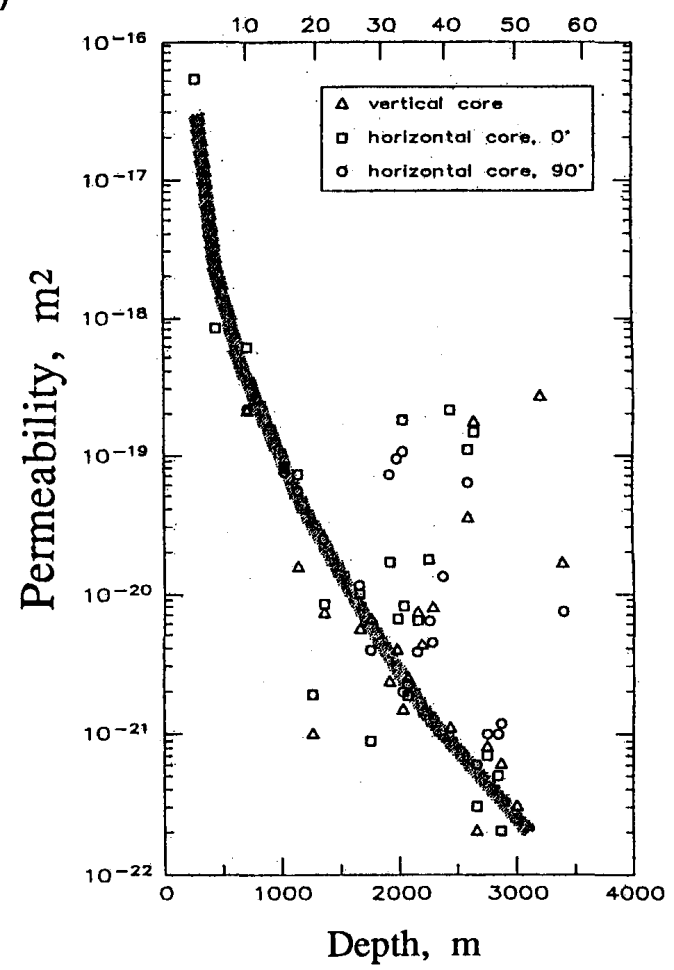

Figure 3. Permeability near a fault zone. a) Nojima fault, Japan [Ito et al. 1998]. b) Cajon Pass, California [Morrow and Byerlee, 1992].

shows the stress on the fault plane as a function of slip. An earthquake is viewed as a stress release process on a surface $S$ where, at the initiation of an earthquake, the initial (before an earthquake) shear stress on the fault plane $\sigma_{0}$ drops to a constant dynamic friction $\sigma_{f}$. If the condition for instability is satisfied [Brace and Byerlee, 1966; Scholz, 1990], rapid fault slip motion begins and eventually stops. At the end, the stress on the fault plane is $\sigma_{1}$ (final stress) and the average slip (offset) is $D$. For the example shown in Figure $4 \mathrm{a}, \sigma_{f}=\sigma_{1}$. The difference $\Delta \sigma_{s}=\sigma_{0}-\sigma_{1}$ is the static stress drop, and the difference $\Delta \sigma_{d}$ $=\sigma_{0}-\sigma_{f}$ is the driving stress of fault motion and is usually called the dynamic stress drop or effective tectonic stress [Brune, 1970]. During this process, the potential energy (strain energy plus gravitational energy) of the system, $W$, drops to $W-\Delta W$ where $\Delta W$ is the strain energy drop, and seismic wave is radiated carrying energy $E_{R}$. Then the energy budget can be written as

$$
\Delta W=E_{R}+E_{F}+E_{G}
$$

where $E_{F}$ is the frictional energy loss given by $E_{F}=\sigma_{f} D S$, and $E_{G}$ is the fracture energy. Knopoff [1958], Dahlen [1977] and Kostrov [1974] showed that $\Delta W=\bar{\sigma} D S$ where $\bar{\sigma}=\left(\sigma_{0}+\sigma_{1}\right) / 2$ is the average stress during faulting. From (5), we obtain

$$
\begin{gathered}
E_{R}=\left(\sigma_{0}+\sigma_{1}\right) D S / 2-\sigma_{f} D S-E_{G}=(1 / 2)\left(2 \Delta \sigma_{d}-\Delta \sigma_{\mathrm{s}}\right) D S-E_{G} \\
=M_{0}\left(2 \Delta \sigma_{d}-\Delta \sigma_{s}\right) / 2 \mu-E_{G}
\end{gathered}
$$

where $M_{0}=\mu D S$ is the seismic moment, and $\mu$ is the rigidity. This is a simple but fundamental relationship which does not involve major assumptions. As we will show later, the fracture energy $E_{G}$ can be ignored for large shallow earthquakes, and (6) can be written as

$$
E_{R}=M_{0}\left(2 \Delta \sigma_{d}-\Delta \sigma_{s}\right) / 2 \mu
$$

This relation can be derived with a simple analogous spring system, and can be shown to be consistent with that 


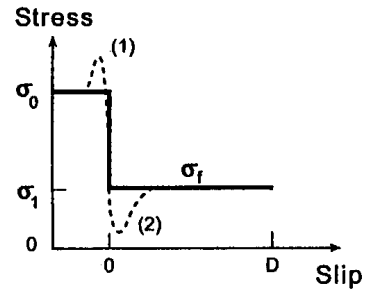

a.

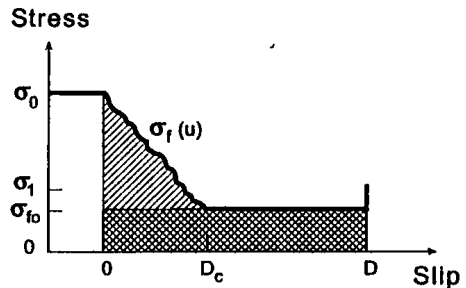

b.
Figure 4. Illustration of simple stress release patterns during faulting. a) Simple case. b) Slip-weakening model. Hatched and cross-hatched areas indicate the fracture energy and frictional energy loss, respectively.

derived from more rigorous relations for continuum. A similar relation has been used in seismology [e.g. Savage and Wood, 1971], but this particular form introduced here is useful because $E_{R}$ is expressed in terms of the specific physical parameters $\Delta \sigma_{s}$ and $\Delta \sigma_{d}$ which directly characterize the stress release process on the fault plane.

The variation of stress during faulting can be more complex than shown in Figure $4 \mathrm{a}$. For example, the stress may increase in the beginning of the slip motion (curve (1) in Figure 4a) because of loading caused by advancing rupture, or of a specific friction law such as the state-rate dependent friction law [Dieterich, 1979a, 1979b]. In fact, seismological inversion studies have shown this increase [Quin, 1990; Miyatake, 1992; Mikumo and Miyatake, 1993; Beroza and Mikumo, 1996; Ide, 1997; Bouchon, 1997]. However, this increase is of short duration and the amount of slip during this stage is small so that little energy is radiated. Thus, we will not include it in our energy budget.

Also, the friction may not be constant during faulting. It may drop drastically in the beginning and later resume a somewhat larger value (curve (2) in Figure 4a), or it may decrease gradually to a constant level (Figure 4b). The latter is called a slip-weakening process. These models have been considered in Brune [1970], Heaton [1990], Kikuchi and Fukao [1988], Kikuchi [1992], Kanamori [1994], Winslow and Ruff [1999], and Thio [1996].

If the friction is not constant, the rupture dynamics is complicated, but for the energy budget considered here, we formulate this problem referring to a simple case shown in Figure $4 \mathrm{~b}$. The friction $\sigma_{f}$ gradually drops to a constant value $\sigma_{f 0}$ until the slip becomes $D_{c}$. In general the final stress $\sigma_{1}$ can be different from $\sigma_{f 0}$. Then, we define the average friction $\bar{\sigma}_{f}$ by

$$
\bar{\sigma}_{f}=\frac{1}{D} \int_{0}^{D} \sigma_{f}(u) d u
$$

where $u$ is the slip (offset) on the fault plane. Then, equation (6') can be written as

$$
E_{R}=M_{0}\left(2 \Delta \bar{\sigma}_{d}-\Delta \sigma_{s}\right) / 2 \mu
$$

where

$$
\Delta \bar{\sigma}_{d}=\sigma_{0}-\bar{\sigma}_{f}
$$

Here, $\Delta \bar{\sigma}_{d}$ defined by (9) can be called the average dynamic stress drop. If friction drops rapidly, $\Delta \bar{\sigma}_{d}$ is the same as $\Delta \sigma_{d}$, but if friction drops very gradually to $\sigma_{1}$, then fault motion becomes quasi-static with no energy radiation, and $\bar{\sigma}_{f}$ defined above would be close to the average stress $\left(\sigma_{0}+\sigma_{1}\right) / 2$. Then $\Delta \bar{\sigma}_{d}=(1 / 2) \Delta \sigma_{s}$, and $E_{R}$ $\approx 0$ from (8). We will use $\Delta \bar{\sigma}_{d}$ in this paper, but the following alternative interpretation is also useful.

We can interpret the slip weakening process in terms of the breakdown process at the advancing front of an earthquake rupture. Then the total energy loss, $\bar{\sigma}_{f} D S$ can be divided into two parts,

$$
\bar{\sigma}_{f} D S=S\left[\sigma_{f 0} D+\int_{0}^{D_{c}}\left(\sigma_{f}(u)-\sigma_{f 0}\right) d u\right]
$$

The first term can be interpreted as frictional energy (crosshatched area in Figure $4 \mathrm{~b}$ ), and the second term, the fracture energy (hatched area in Figure 4b). Then, equation (6') can be written as

$$
\begin{gathered}
E_{R}=M_{0}\left(2 \Delta \sigma_{d}-\Delta \sigma_{s}\right) / 2 \mu \\
-S \int_{0}^{D_{c}}\left(\sigma_{f}(u)-\sigma_{f 0}\right) d u
\end{gathered}
$$

where

$$
\Delta \sigma_{d}=\sigma_{0}-\sigma_{f 0}
$$

Here, the definition of the dynamic stress drop is the same as the traditional one, but the fracture energy $E_{G}=S \int_{0}^{D_{c}}\left(\sigma_{f}(u)-\sigma_{f 0}\right) d u$ needs to be subtracted from the right-hand side of (6') to obtain $E_{R}$.

\section{FRACTURE ENERGY}

The estimates of fracture energy for earthquakes vary over a wide range. The specific fracture energy $G^{*}$ (fracture energy per unit area) ranges from 1 to $10^{8} \mathrm{~J} / \mathrm{m}^{2}$ [Kostrov 
and Das, 1988]. The largest values are derived from seismic data on the assumption that rupture is arrested by a barrier [Aki, 1979] and may not be representative of the average fracture energy of earthquakes. Husseini [1977] estimated $G^{*}$ to be on the order of $10^{5} \mathrm{~J} / \mathrm{m}^{2}$. Scholz [1990] quotes a range $10^{6}$ to $10^{7} \mathrm{~J} / \mathrm{m}^{2}$.

The fracture energy can be related to the rupture velocity. For simplicity, we use a Mode III (longitudinal shear) crack model in the following, but we can qualitatively develop a similar argument for other crack geometries.

We take a Cartesian coordinate system $(x, y, z)$, and consider an infinitely long crack extending in $z$ direction. The crack growth is in $x$ direction. Let $2 c$ be the width of the crack in $x$ direction. The crack is under uniform stress $\sigma_{0}$ and friction $\sigma_{f}$, both in $z$ direction. In actual faulting, $\sigma_{f}$ is likely to vary during faulting, but here we assume it to be constant. Then,

$$
\begin{gathered}
\Delta W=\left(\sigma_{0}+\sigma_{f}\right) D S / 2=\left(\sigma_{0}-\sigma_{f}\right) D S / 2+\sigma_{f} D S \\
=\Delta W_{1}+\sigma_{f} D S
\end{gathered}
$$

where

$$
\Delta W_{1}=\left(\sigma_{0}-\sigma_{f}\right) D S / 2=\pi c^{2}\left(\sigma_{0}-\sigma_{f}\right)^{2} / 2 \mu
$$

In the above, the relations $S=2 c$ and $\left(\sigma_{0}-\sigma_{f}\right)=2 \mu D / \pi c$ [Knopoff, 1958] are used.

The static energy release rate (specific fracture energy) $G^{*}$ is given by

$$
G^{*}=K^{2} / 2 \mu=\pi c\left(\sigma_{0}-\sigma_{f}\right)^{2} / 2 \mu
$$

where $K=\left(\sigma_{0}-\sigma_{f}\right)(\pi c)^{1 / 2}$ is the stress intensity factor [Dmowska and Rice, 1986; Lawn, 1993; Freund, 1998]. From (14) and (15),

$$
\mathrm{d}\left(\Delta W_{1}\right)=2 G^{*} \mathrm{~d} c
$$

Following Kostrov [1966], Eshelby [1969], and Freund [1972], the energy release rate, $G$, for a crack growing at a rupture speed $V$ is given approximately by

$$
G=G^{*} g(V)
$$

where $g(V)$ is a universal function of $V$. For a Mode III crack, it is given by

$$
g(V)=[(\beta-V) /(\beta+V)]^{1 / 2}
$$
is

where $\beta$ is $S$-wave velocity. Then, the fracture energy

$$
\begin{aligned}
E_{G}= & \int G d S=2 \int_{0}^{c} G^{*} g(V) d c \\
& =g(V) \int d\left(\Delta W_{1}\right)=g(V) \Delta W_{1}
\end{aligned}
$$

which becomes small compared with the strain energy involved as $V$ increases to the limiting velocity $\beta$, because $g(V)$ approaches 0 in this limit. For most large shallow earthquakes, it is generally established that the rupture velocity is about 75 to $85 \%$ of $\beta$, [Heaton, 1990] and we can neglect $E_{G}$.

\section{LINK BETWEEN MICROSCOPIC AND MACROSCOPIC PROCESSES}

Our fault model consists of many faults (microfaults or subfaults) each one of which radiates seismic energy following the stress release process described above. We cannot distinguish every fault, but what we observe seismologically is the total energy radiated from all of them. Using equation (8), the total energy is given by

$$
\begin{aligned}
E_{R} & =\sum E_{R_{i}}=\sum M_{0_{i}}\left(2 \Delta \bar{\sigma}_{d_{i}}-\Delta \sigma_{s_{i}}\right) / 2 \mu \\
& =M_{0}\left(2 \Delta \bar{\sigma}_{d}-\Delta \sigma_{s}\right) / 2 \mu
\end{aligned}
$$

where the average dynamic stress drop, $\Delta \bar{\sigma}_{d}$, and the average static stress drop, $\Delta \sigma_{s}$, are the macroscopic parameters defined by

$$
\Delta \bar{\sigma}_{d}=\sum M_{0_{i}} \Delta \bar{\sigma}_{d_{i}} / M_{0}
$$

and

$$
\Delta \sigma_{s}=\sum M_{0_{i}} \Delta \sigma_{s_{i}} / M_{0}
$$

Here subscript $i$ denotes the $i$-th subfault. Equations 21 and 22 show that the macroscopic stress drops $\Delta \bar{\sigma}_{d}$ and $\Delta \sigma_{s}$ are given as weighted averages of the stress drops for each subfault. The weight is the seismic moment of each subfault.

With this interpretation, we can tie the microscopic processes occurring on a fault plane to the macroscopic parameters, such as $M_{0}$ and $E_{R}$, measurable with seismological methods. This is similar to the treatise in the kinetic theory of gas, in which macroscopic thermodynamic parameters like temperature and pressure are tied to the kinetic energy of molecules. 
Since the rupture pattern on a fault plane is so complex that we cannot use a simple stress pattern shown in Figure 4 to represent the entire faulting. However, we can use the static and dynamic stress drops defined by (21) and (22) to represent the overall state of stress during seismic rupture.

\section{INTERPRETATION}

We use the macroscopic seismic parameters, $M_{0}$ and $E_{R}$, which are now tied to microscopic processes through equations 20, 21 and 22 for interpreting seismic data. Specifically, we use the ratio $\tilde{e}=E_{R} / M_{0}$. This ratio, $\tilde{e}$, multiplied by $\mu$ was introduced in seismology in the 1960's as "apparent stress" [ $\mathrm{Aki}, 1966 ;$ Wyss and Brune, $1968 ;$ Wyss, 1970a, 1970b]. It is usually expressed as a product of the efficiency $\eta$ and the average stress $\bar{\sigma}=\left(\sigma_{0}+\sigma_{1}\right) / 2$, neither of which can be directly determined seismologically. Nevertheless, the apparent stress, combined with static stress drop, provided useful information for the state of stress in different regions. Wyss [1970a] showed that the apparent stress of earthquakes on ridges do not differ much from those in trenches. The difficulty with the apparent stress was in difficulty in accurately computing the radiated energy. Although this difficulty still exists [e.g. Singh and Ordaz, 1994], the accuracy of energy estimates has improved [Choy and Boatwright, 1995], and we revive the use of $\tilde{e}$. In this paper, using equation 20 , the relationship is cast in terms of the static and dynamic stress drops as follows.

$$
\tilde{e}=E_{R} / M_{0}=\left(2 \Delta \bar{\sigma}_{d}-\Delta \sigma_{s}\right) / 2 \mu
$$

The quantity $\tilde{e}$ can be interpreted as a non-dimensional radiated energy scaled with $M_{0}$, the static size of the earthquake, and is called the scaled energy.

Qualitatively, if the friction drops rapidly, fault motion would be accelerated rapidly, and more energy will be radiated for a given $M_{0}$, and results in large $\tilde{e}$. In contrast, if the friction drops gradually, the fault motion is accelerated slowly thereby radiating less energy than the case for sudden drop in friction; this would result in small $\tilde{e}$. Thus, $\tilde{e}$ which can be determined with the conventional seismological method can be used to infer the rupture behavior.

We can state the above behavior more quantitatively as follows. As shown in Figure 4a, if the friction drops rapidly, $\Delta \bar{\sigma}_{d}$ is comparable, or larger than $\Delta \sigma_{s}$, and $\tilde{e}$ given by equation 23 is of the order of $\Delta \sigma_{s} / 2 \mu$. In contrast, if friction drops gradually, $\bar{\sigma}_{f}$ defined by (7) approaches the average stress $\left(\sigma_{0}+\sigma_{1}\right) / 2$; then $\Delta \bar{\sigma}_{d} \approx$ $(1 / 2) \Delta \sigma_{s}$, and $\tilde{e} \approx 0$.

Figure $5 \mathrm{a}$ shows the observed relation between $E_{R}$ and $M_{0}$, and Figure $5 \mathrm{~b}$ shows $\tilde{e}$ as a function of $M_{W}$.
Although the determination of $M_{0}$ can be made accurately, the determination of $E_{R}$ is still subject to large uncertainties. The values of $E_{R}$ estimated for the same earthquake by different investigators often differ by more than a factor of 10 [Singh and Ordaz, 1994; Mayeda and Walter, 1996]. In particular, the values determined from
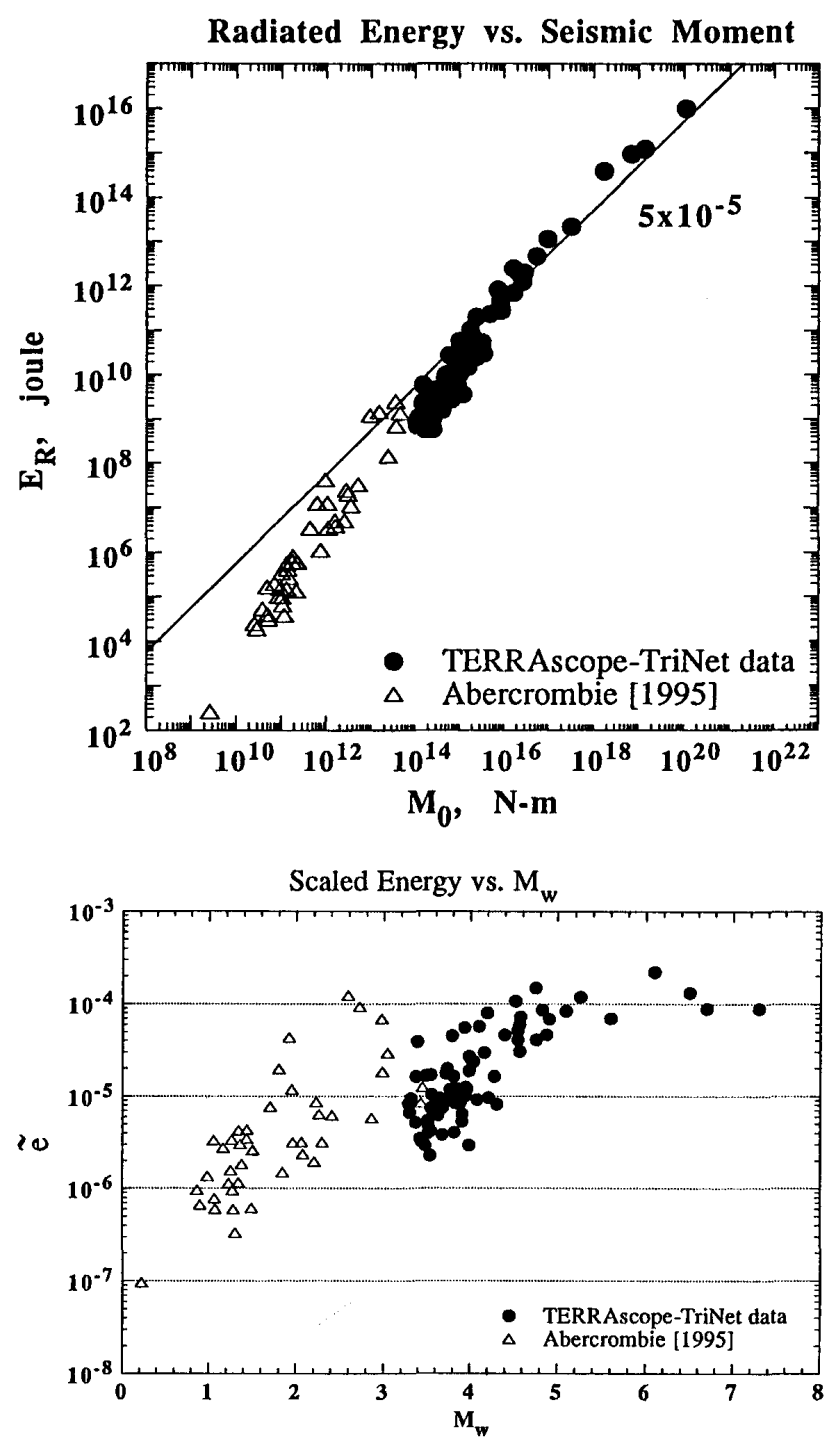

Figure 5. a). Relation between the radiated energy $E_{R}$ and the seismic moment $M_{0}$. The data for large earthquakes (solid circle) are from southern California [updated from Kanamori et al., 1993], and those for small earthquakes (open triangles) are taken from Abercrombie [1995]. b) The scaled energy, $\tilde{e}=E_{R} / M_{0}$, computed as a function of $M_{W}$. Note that the values of $\tilde{e}$ for small earthquakes are 10 to 100 times smaller than those for large earthquakes. 
teleseismic data tend to be consistently smaller than those determined from regional data. This difficulty is mainly due to the complex propagation effects. Because of these uncertainties, the relation between $E_{R}$ and $M_{0}$ has not been given close attention.

Figures $5 \mathrm{a}$ and $5 \mathrm{~b}$ include two data sets. The data for large earthquakes $\left(M_{W} \geq 3.5\right)$ are obtained in southern California using broad-band seismic data. The results obtained by Kanamori et al. [1993] have been slightly revised and updated using more recent data from TriNet, a broad-band seismic network in southern California [Mori et al., 1998]. In these studies, broad-band data at relatively short distances were used, and the propagation and site effects were removed empirically. The results of a recent study by Mayeda and Walter [1996] who used coda waves to determine the radiated energy agree with those of Kanamori et al. [1993] within a factor of 2, with Mayeda and Walter's values being slightly larger. With the recent deployment of a large number of broad-band instruments in southern California (TriNet, Mori et al. [1998]), the propagation and site effects can be calibrated more accurately with many high-quality data at short distances. The new calibration data suggest that the results obtained earlier with TERRAscope are probably accurate within a factor of 3 .

The data for smaller earthquakes in Figures $5 \mathrm{a}$ and $5 \mathrm{~b}$ were obtained by Abercrombie [1995] using the down-hole (2.5 km deep) seismic data recorded in the Cajon drilling site in southern California [Zoback and Lachenbruch, 1992]. A distinct advantage of using down-hole data is that they are free from the complex free-surface effects and the large attenuation near the recording site. These are the main factors that cause the large uncertainties in the results obtained with surface instruments, especially for small earthquakes. Although only one station was available, the data set covers a fairly large azimuthal range (approximately $150^{\circ}$ ) so that the effects of radiation pattern and directivity were averaged out. Most events are within relatively short distances, $25 \mathrm{~km}$, and the wave forms exhibit clean impulsive characters. Thus, these observations are considered among the most reliable for small earthquakes.

\section{Large $\left(M_{W} \geq 4.5\right)$ Earthquakes}

Figure $5 \mathrm{~b}$ shows that the values of $\tilde{e}$ is about $5 \times 10^{-5}$ to $2 \times 10^{-4}$ for large earthquakes. If the static stress drop $\Delta \sigma_{s}$ is 10 to 100 bars, this result indicates (equation 8 ) that the dynamic stress drop, $\Delta \bar{\sigma}_{d}$, is 20 to 110 bars for large earthquakes, comparable to, or slightly larger than, the static stress drop $\Delta \sigma_{s}$.

Our interpretation is that, for large earthquakes, melting and fluid pressurization reduce dynamic friction thereby causing rapid brittle failure resulting in a relatively large $\tilde{e}$. Since both $\Delta \sigma_{s}$ and $\Delta \bar{\sigma}_{d}$ are of the order of 100 bars, and the friction is low, the entire process must be occurring at a stress level comparable to the static and dynamic stress drops, about 100 bars (Figure 4a). This is consistent with the result of Beroza and Zoback [1993] and Zoback and Beroza [1993] who found from the diversity of aftershock mechanisms that the friction during the 1969 Loma Prieta, California, earthquake was very low. Also Spudich [1992] and Spudich et al. [1998] inferred from the rotation of slip vectors that the absolute stress during faulting of several earthquakes is comparable to stress drops. The assumption in these studies is that the slip direction is subparallel to the frictional stress on the fault plane.

\section{Small $\left(\mathrm{M}_{\mathrm{W}}<2\right)$ Earthquakes}

A striking feature seen in Figures $5 \mathrm{~b}$ is that the ratio, $\tilde{e}$, for small earthquakes is approximately 10 to 100 times smaller than that for large earthquakes, i.e. small earthquakes appear to be less efficient in wave radiation than large earthquakes. Even if we allow for the potentially large uncertainties in energy estimation, this difference appears to be too large to be attributed to experimental errors, and probably reflects the real difference in the rupture dynamics between small and large earthquakes. The transition occurs between $M_{W}=2.5$ and 5 . Although Figures $5 \mathrm{a}$ and $5 \mathrm{~b}$ show the results only from the two specific data sets, many other studies show a similar transition over this magnitude range [e.g. Thatcher and Hanks, 1973; Fletcher and Boatwright, 1991; Boatwright et al., 1991; Mayeda and Walter, 1996; Thio, 1996; Zhu, 1998]. It is interesting to note that figure 7 of Thatcher and Hanks [1973] showing the relation between $M_{0}$ and $M_{L}$, if combined with their figure $10\left(E_{R} v s . M_{L}\right)$, could be interpreted as showing this transition.

Referring to equations 7 and 9, we interpret this result in terms of a gradual drop in friction. Because the thermal energy involved is not large enough to reduce friction, the stress change can be gradual as shown in Figure $4 \mathrm{~b}$. This means that fracture energy, $E_{G}$, given in equation 6 or that defined by the second term of equation 10 is large for small earthquakes. As mentioned earlier, the fracture energy for large earthquakes is considered to be small but, for small earthquakes, there is no direct evidence for small fracture energy, i.e. small earthquakes could be significantly less brittle than large earthquakes.

McGarr [1999] suggests, on the basis of the data for the apparent stress, that the upper bound of efficiency of earthquakes is about 0.06. Our conclusion on small earthquakes is qualitatively consistent with McGarr's [1999]. However, our conclusion suggests that the efficiency for large earthquakes (e.g. $M_{W}>6$ ) could be considerably higher than that for small earthquakes. 


\section{Models for Small and Large Earthquakes}

Using the results obtained above, we present here a schematic model contrasting small and large earthquakes.

First we assume that $\sigma_{0}$ is the same everywhere along a fault zone. Then, Figure 6 illustrates representative stress variations for small and large earthquakes. We assume that the stress on the fault plane drops linearly from $\sigma_{0}$ until the slip reaches a critical value, $D_{C}$, where the stress is equal to a constant frictional stress $\sigma_{f 0}$. The stress eventually drops to almost 0 if slip exceeds $D_{T}$ when melting or pressurization reduces friction. Figure $5 \mathrm{~b}$ shows that this transition occurs at $M_{W}=2.5$ to 5 , which suggests that $D_{T}=2$ to $30 \mathrm{~cm}$ (equation 2).

We let $D_{\mathrm{S}}$ and $D_{L}$ be the total displacement for small and large earthquakes, respectively. For small earthquakes, $D_{C}<D_{S}<D_{T}$, and for large earthquakes, $D_{L}>>D_{T}$. Then for large earthquakes,

$$
\begin{aligned}
& E_{R}=\Delta W-E_{F}-E_{G} \\
= & D_{L} S\left[\frac{\sigma_{0}+\sigma_{1}}{2}-\sigma_{f 0}\left(\frac{D_{T}}{D_{L}}\right)-\frac{\sigma_{0}-\sigma_{f 0}}{2}\left(\frac{D_{C}}{D_{L}}\right)\right]
\end{aligned}
$$

Since $D_{L}>>D_{T}>D_{C}$, and $\sigma_{1} \approx 0$,

$$
\tilde{e}=\frac{\Delta \sigma_{s}}{2 \mu}, \text { where } \Delta \sigma_{s}=\sigma_{0}
$$

In contrast, for small earthquakes,

$$
\begin{aligned}
& E_{R}=\Delta W-E_{F}-E_{G} \\
& =D_{S} S\left[\frac{\sigma_{0}+\sigma_{f 0}}{2}-\sigma_{f 0}-\frac{\sigma_{0}-\sigma_{f 0}}{2}\left(\frac{D_{C}}{D_{S}}\right)\right] \\
& =D_{S} S \frac{\left(\sigma_{0}-\sigma_{f 0}\right)}{2}\left(1-\frac{D_{C}}{D_{S}}\right)
\end{aligned}
$$

Thus,

$$
\tilde{e}=\frac{\Delta \sigma_{s}}{2 \mu}\left(1-\frac{D_{C}}{D_{S}}\right), \text { where } \Delta \sigma_{s}=\sigma_{0}-\sigma_{f 0}
$$

In this case, $\Delta \sigma_{s}$ (small earthquakes) $<\Delta \sigma_{s}$ (large earthquakes), but the difference would be small, about a factor of 2 or so. On the other hand, the scaled energy, $\tilde{e}$, can be very different. If $D_{S}$ is comparable to $D_{C}$ for small earthquakes, then $\tilde{e}$ can be very small. This is the reason why we have the large difference in $\tilde{e}$ between large and
Energy Budget of Earthquakes
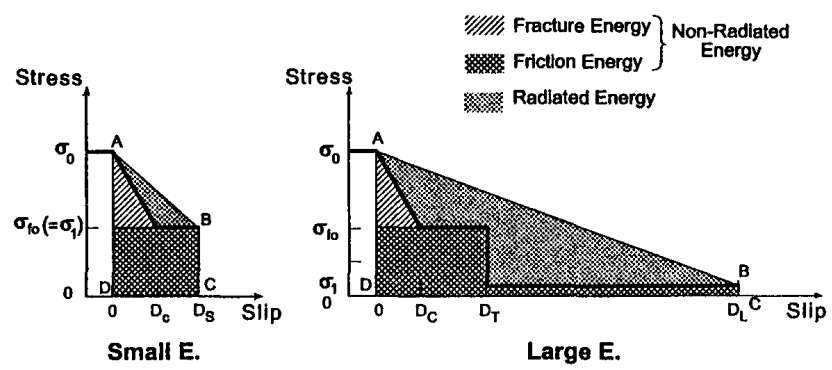

Figure 6. Schematic stress release patterns for small (left) and large earthquakes (right). Hatched, cross-hatched, and dotted areas represent the fracture energy, frictional energy loss and radiated energy, respectively.

small earthquakes, even if the static stress drop is about the same. Actually, $\sigma_{0}$ may vary considerably along a fault zone. If $\sigma_{0}$ is large for small earthquakes, then we can have $\Delta \sigma_{s}($ small $)=\Delta \sigma_{s}($ large $)$, yet $\tilde{e}$ can be still very small for small earthquakes if $D_{S} \approx D_{C}$. Actually, a large $\sigma_{0}$ for small earthquakes may not be unreasonable considering the possibility of local stress concentration. In any case, the actual condition can be very heterogeneous, but as a whole, some mechanism as illustrated in Figure 6 is probably responsible for the difference between large and small earthquakes.

\section{IMPLICATIONS}

\section{State of Stress}

The results obtained for large earthquakes suggest that the average stress level along mature faults where large earthquakes occur must be low because of the dominant thermal effects such as frictional melting and fluid pressurization. Because of melting or pressurization, a fault zone is self-organized into a low stress state. That is, even if the stress was high in the early stage of fault evolution, it would eventually settle in a low stress state after many large earthquakes. This state of stress is consistent with the generally held view that the absence of heat flow anomaly along the San Andreas fault suggests a shear strength of about 200 bars or less [Brune et al., 1969; Lachenbruch and Sass, 1980].

The stress in the crust away from active mature faults can be high as has been shown by many in-situ measurements of stress [McGarr, 1980; Brudy et al., 1997]. The stress difference is large, and a kbar type stress may be involved in small earthquakes, but the events are in general so small that it is hard to determine the stress parameters accurately. What is important, though, is that as long as the length of the fault is small, the state of 


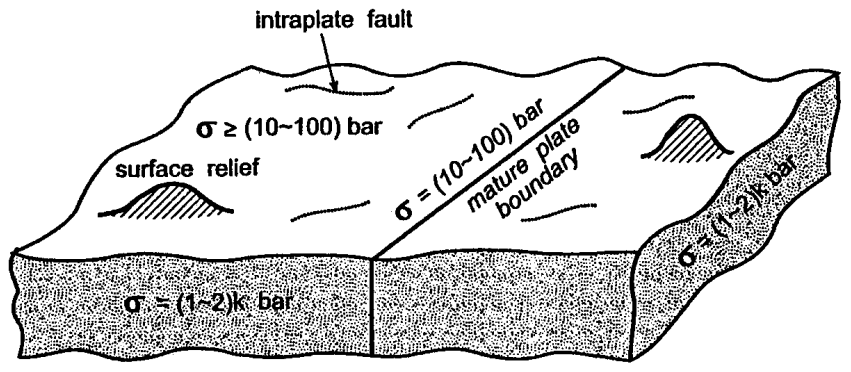

Figure 7. Schematic diagram showing the magnitude of the stresses in Earth's crust. Modified from [Kanamori, 1980].

stress in the fault zone would not affect the regional stress drastically. However, as the fault grows to some length (e.g. Japanese intra-plate earthquakes like Tango, Tottori, Nobi etc.), then some sort of self-organization occurs and the fault settles at a stress level somewhat higher than that on more active plate boundaries.

This type of stress distribution has been suggested from seismic data [Figure 7, Kanamori, 1980], and from stress orientations near major plate boundaries [Mount and Suppe, 1987; Zoback et al., 1987].

\section{Magnitude-frequency Relationship for Mature Faults}

One probable consequence of sudden reduction in friction when slip exceeds a threshold value would be runaway rupture. In this context, an interesting observation is the magnitude-frequency relationship for some mature plate boundaries such as the San Andreas fault and some subduction zones. For example, the absence of events with magnitude between 6.5 and 7.5 on the San Andreas fault in southern California, despite the occurrence of magnitude 8 earthquake in 1957 (Fort Tejon earthquake) and the average repeat time of about a few hundred years [Sieh, 1984], has been thought somewhat odd. Figure $8 \mathrm{a}$ shows the magnitude-frequency relation taken from Wesnousky [1994]. Earthquakes with $M$ from 6 to 7 appear to be fewer than expected for the conventional magnitude-frequency relationship. A similar observation has been made for the Nankai trough in Japan [Masataka Ando, 1999, personal communication] as shown in Figure 8b. In this region, many earthquakes with $M \geq 8$ are documented well (Figure 9), but almost no earthquakes with $7<M<8$ have occurred there since 1900. These observations can be interpreted in terms of the runaway process discussed above. As the magnitude exceeds a threshold value, about 6.5 for the San Andreas and 7 for the Nankai trough, the friction drops and fault slip cannot stop until it reaches some limit imposed by the regional seismogenic structure or loading geometry. This is a runaway situation caused by dynamic effects of faulting.

If the specific fracture energy, $G^{*}$, is constant, the Griffith type cracks are inherently unstable, i.e. if the crack length exceeds a threshold, the crack will runaway. So, in this sense all earthquakes, small and large, can get into runaway rupture. However, $G^{*}$ is not constant in real fault zones, and the place where $G^{*}$ is large acts as a barrier to stop rupture propagation $[A k i, 1979]$. Then the question is what is the probability of some barriers stopping the rupture. The easiest way to look at this situation is to use the stress intensity factor $K$ which is given by $\left(\sigma_{0}-\sigma_{f}\right)(\pi l)^{1 / 2}$ for a Mode III crack [e.g. Dmowska and Rice, 1986] where $l$ is the crack length. As the fault grows, $l$ and $D$ increase. When $D$ exceeds $D_{T}$, friction, $\sigma_{f}$, drops (see Figure 6). The combined effect of the decreasing $\sigma_{f}$ and increasing $l$ increases $K$. Since the crack extension force is proportional to $K^{2}$, the fault rupture becomes harder to stop and runaway rupture is more likely to occur.

The magnitude-frequency relationship is usually understood as a manifestation of heterogeneity of fault structure [Scholz and Aviles, 1986; Okubo and Aki, 1987; Aviles et al., 1987]. In addition to this static feature, slipcontrolled dynamic runaway process could be an important element that determines the earthquake statistics for mature faults.

\section{Seismic Breakaway Phase}

In a series of papers, Ellsworth and Beroza [1995, 1998] and Beroza and Ellsworth [1996] showed that the moment rate of many earthquakes is initially low but after some time it grows rapidly. They called this sudden increase in the moment rate a breakaway phase. The breakaway phase could be a manifestation of the slipcontrolled runaway rupture. However, our model has a highly heterogeneous distribution of strength and would not explain the scaling relation proposed by Ellsworth and Beroza [1995, 1998] and Beroza and Ellsworth [1996]. Similar observations, on various time scales, have been made by Umeda [1990, 1992], and Kikuchi [1997].

\section{Slip Behavior of a Plate Boundary}

The thermally-controlled model discussed above is inherently non-linear in the sense that slip controls the slip behavior. In such a non-linear system, it is possible that an infinitesimally small perturbation in the initial condition may lead to a significantly different behavior. In this context, the historical sequence along the Nankai trough is interesting. Figure 9 shows the sequence determined by a series of studies of Imamura [1928], Ando [1975], and Ishibashi [1998]. An interesting event is the one in 1605 . This event caused widespread tsunami along the Japanese coast, but no significant evidence for shaking has been documented [Ishibashi, 1981]. Although the evidence is qualitative, the historical data for this region are generally considered reliable. This evidence suggests 

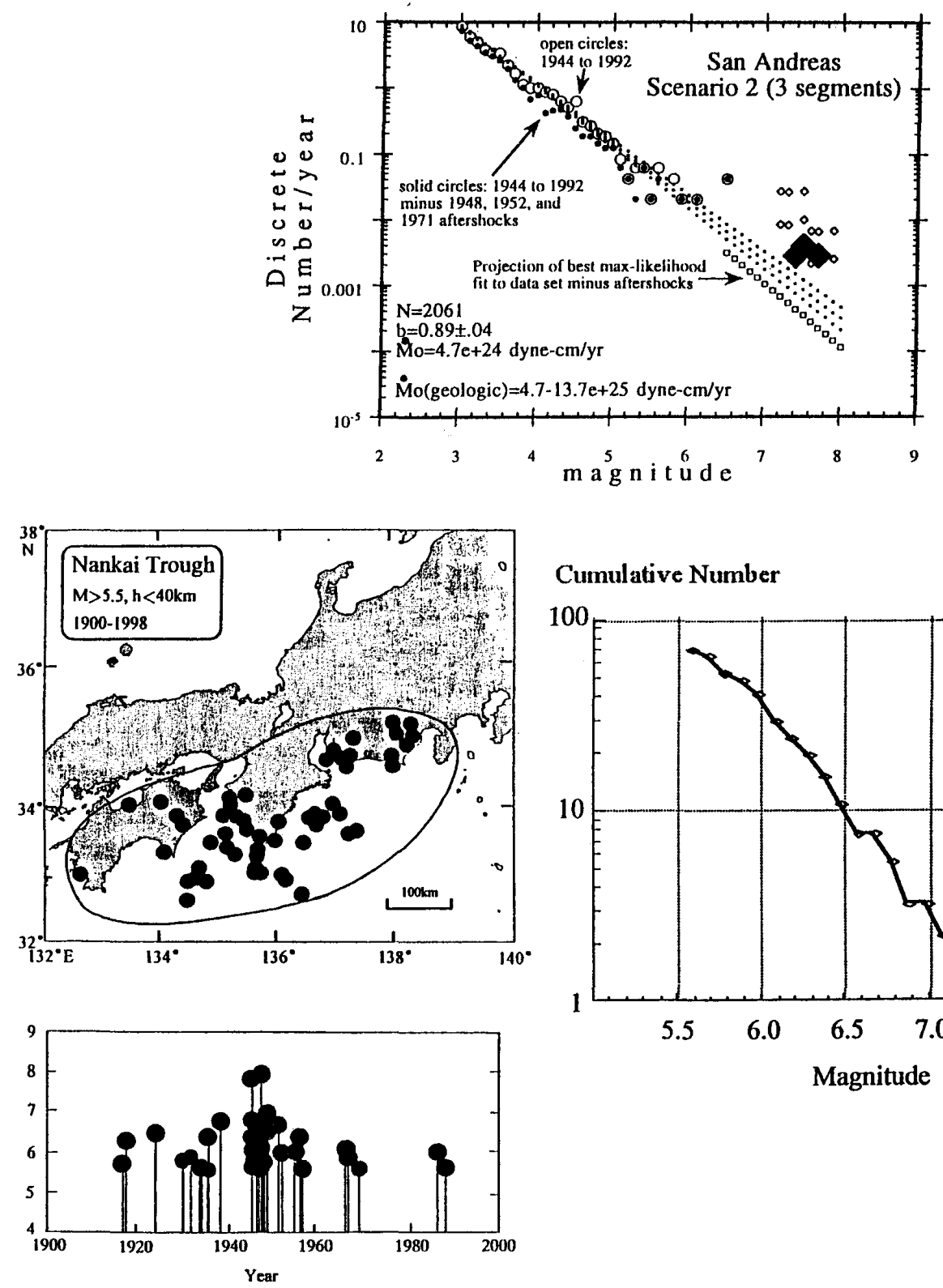

Cumulative Number

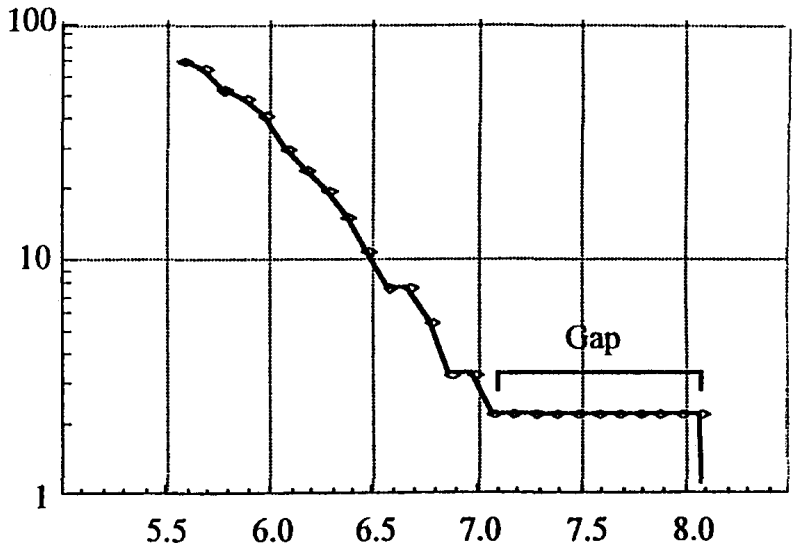

Magnitude

Figure 8 a). Magnitude-frequency relationship for the San Andreas fault, California [Wesnousky, 1994]. b). The same for the Nankai trough, Japan [Masataka Ando, written communication, 1999].

that the 1605 earthquake was a tsunami earthquake in the sense defined by Kanamori [1972]. We suggest that the general style of earthquakes along a plate boundary (i.e. brittle ordinary earthquake, slow tsunami earthquake, or creep) is determined by the properties of the boundary (e.g. age of the subducting plate, sediment structure, roughness of the subducting plate, convergence rate etc., [Ruff and Kanamori, 1983; Uyeda and Kanamori, 1979; Scholz and Campos, 1995]), but considerable perturbation from the average behavior could occur because of the non-linear nature of thermally-controlled mechanism. A slow tsunami earthquake could occasionally occur at a plate boundary where ordinary earthquakes regularly occur. This is a speculative interpretation, and the possibility that the 1605 earthquake was caused by some other mechanisms remains, but considering the significant thermal effects on fluid-filled subduction boundaries, this interpretation is plausible. Yamashita [1998] showed that fluid migration in a porous fault zone with spatially heterogeneous fracture strength can produce irregular event sequences. Although 
Yamashita's model is for a quasi-static case, and is not directly applicable to dynamic rupture propagation, a similar model would produce variable dynamic rupture patterns.

\section{Ground Motion from Large Earthquakes}

The effect of a pulse-like near-field ground motion on large structures is becoming an important engineering problem [Heaton, 1990; Heaton et al., 1995; Hall et al., 1995]. However, very few recordings of near-field ground motion from large earthquakes exist. In modeling studies, the records from small earthquakes are used to estimate ground motions from hypothetical large earthquakes. This is a reasonable approach but the possibility exists that the slip velocity during very large earthquakes could be significantly larger than that for small earthquakes because of reduction of friction caused by large displacement.

\section{CONCLUSION}

The thermal budget during seismic slip suggests that frictional melting and fluid pressurization can play a key role in rupture dynamics of large earthquakes. In a simple model of faulting under frictional stress $\sigma_{f}$, the temperature increases with $\sigma_{f}$ and the earthquake magnitude, $M_{W}$. If the slip zone is thin and heat transfer is mainly by conduction, the thickness of the heated zone, $w$, is of the order of a few $\mathrm{mm}$ for a seismic time scale of about $10 \mathrm{sec}$. Then, even for a modest $\sigma_{f}$, the temperature rise, $\Delta T$, would exceed $1000^{\circ}$ for earthquakes with $M_{W}=5$ to 7 , and melting is likely to occur, and reduce friction during faulting. Another important process is fluid pressurization. If fluid exists in a fault zone, a modest $\Delta T$ of 100 to $200^{\circ}$ would likely increase the pore pressure enough to significantly reduce friction for earthquakes with $M_{W}=3$ to 5 . The microscopic state of stress caused by local melting and pressurization can be tied to macroscopic seismic parameters such as, $M_{0}$ and $E_{R}$, by averaging the stresses in the microscopic states. Since the thermal process is important only for large earthquakes, the dynamics of small and large earthquakes can be very different. This difference is reflected in the observed relation between the ratio $\tilde{e}=E_{R} / M_{0}$ and $M_{W}$. The available seismic data show that $\tilde{e}$ for large earthquakes is 10 to 100 times larger than for small earthquakes. According to this model, mature fault zones such as the San Andreas are at relatively moderate stress levels, but the stress in the plate interior can be high. The fault dynamics described here suggests that once slip exceeds a threshold, runaway rupture could occur. This could explain the anomalous magnitudefrequency relationship observed for some mature faults. Since the thermal state is controlled by the amount of slip, the slip behavior is controlled by the slip itself. This would produce a non-linear behavior, and under certain circumstances, the slip behavior at the same location may vary from event to event. Another important implication is that slip velocity during a large earthquake could be faster than what one would extrapolate from smaller earthquakes.

Acknowledgments. We thank Kenshiro Otsuki for sharing his insight into cataclasites and pseudotachylytes with us. Discussions with Rachel Abercrombie helped us assess the accuracy of energy measurements for small earthquakes. We benefited from the comments on the early version of the manuscript by Yoshio Fukao, Masayuki Kikuchi, Minoru Takeo, and Emily Brodsky. We also thank Toshihiko Shimamoto, Lee Silver, and Yuri Fialko for helpful discussions at various stages of this work. We thank Masataka Ando and Hisao Ito for allowing us to use some of their unpublished figures. This research was partially supported by the U. S. Geological Survey grant 99HQGR0035. Contribution \#8635, Division of Geological and Planetary Sciences, California Institute of Technology.

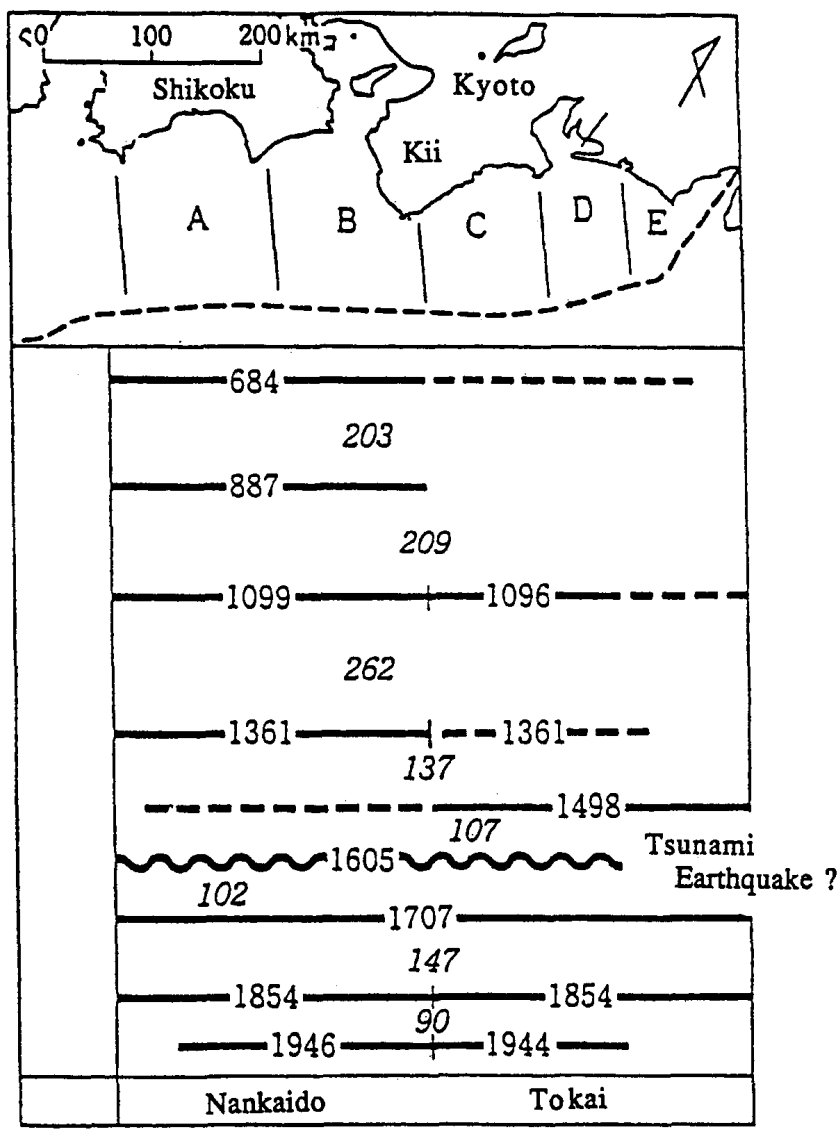

Figure 9. Large earthquakes along the Nankai trough, Japan [Ishibashi and Satake, 1998]. 


\section{REFERENCES}

Abercrombie, R., Earthquake source scaling relationships from -1 to $5 \mathrm{ML}$ using seismograms recorded at $2.5-\mathrm{km}$ depth, $J$. Geophys. Res., 100, 24,015-24,036, 1995.

Abercrombie, R., and P. Leary, Source parameters of small earthquakes recorded at $2.5 \mathrm{~km}$ depth, Cajon Pass, Southern California: Implications for earthquake scaling, Geophys. Res. Lett., 20, 1511-1514, 1993.

Aki, K., Generation and propagation of $G$ waves from the Niigata earthquake ofJune 16,1964 . Part 2. Estimation of earthquake moment, from the $\mathrm{G}$ wave spectrum, Bull. Earthquake Res. Inst. Tokyo Univ., 44, 73-88, 1966.

Aki, K., Characterization of barriers on an earthquake fault, $J$. Geophy. Res., 84, 6140-6148, 1979.

Ando, M., Source mechanisms and tectonic significance of historical earthquakes along the Nankai trough, Japan, Tectonophysics, 27, 119-140, 1975.

Aviles, C. A., C. H. Scholz, and J. Boatwright, Fractal analysis applied to characteristic segments of the San Andreas fault, J. Geophys. Res., 92, 331-344, 1987.

Beeler, N. M., T. E. Tullis, M. L. Blanpied, and J. D. Weeks, Frictional behavior of large displacement experimental faults, J. Geophys. Res., 101, 8697-8715, 1996.

Ben-Zion, Y., and D. J. Andrews, Properties and implications of dynamic rupture along a material interface, Bull. Seismol. Soc. Am., 88, 1085-1094, 1998.

Beroza, G. C., and W. L. Ellsworth, Properties of the seismic nucleation phase, Tectonophysics, 261, 209-227, 1996.

Beroza, G. C., and T. Mikumo, Short slip duration in dynamic rupture in the presence of heterogeneous fault properties, $J$. Geophys. Res., 101, 22,449-22,460, 1996.

Beroza, G. C., and M. D. Zoback, Mechanism diversity of the Loma Prieta aftershocks and the mechanics of mainshockaftershock interaction, Science, 259, 210-213, 1993.

Boatwright, J., J. B. Fletcher, and T. Fumal, A general inversion scheme for source, site and propagation characteristics using multiply recorded sets of moderatesized earthquakes, Bull. Seismol. Soc. Am., 81, 1754-1782, 1991.

Bouchon, M., The state of stress on some faults of the San Andreas system as inferred from near-field strong motion data, J. Geophys. Res., 102, 11,731-11,744, 1997.

Brace, W. F., and J. D. Byerlee, Stick slip as a mechanism for earthquakes, Science, 153, 990-992, 1966.

Brudy, M., M. D. Zoback, K. Fuchs, F. Rumell, and J. Baumgartner, Estimation of the complete stress tensor to 8 $\mathrm{km}$ depth in the KTB scientific drill holes: Implications for crustal strength, J. Geophys. Res., 102, 18,453-18,475, 1997.

Brune, J. N., Tectonic stress and spectra of seismic shear waves from earthquakes, J. Geophys. Res., 75, 4997-5009, 1970.

Brune, J. N., S. Brown, and P. A. Johnson, Rupture mechanism and interface separation in foam rubber models of earthquakes: A possible solution to the heat flow paradox and the paradox of large overthrusts, Tectonophysics, 218 , 59-67, 1993.

Brune, J. N., T. L. Henyey, and R. F. Roy, Heat flow, stress, and the rate of slip along the San Andreas fault,California, J. Geophys. Res., 74, 3821-3827, 1969.
Byerlee, J. D., Friction, overpressure and fault normal compression,, Geophysical Research Letters, 17, 4,741$4,750,1990$.

Cardwell, R. K., D. S. Chinn, G. F. Moore, and D. L. Turcotte, Frictional heating on a fault zone with finite thickness, Geophys. J. Roy. Astron. Soc., 52, 525-530, 1978.

Chester, F. M., and J. S. Chester, Ultracataclasite structure and friction processes of the Punchbowl fault, San Andreas system, California, Tectonophysic, 295, 199-221, 1998.

Choy, G. L., and J. L. Boatwright, Global patterns of radiated energy and apparent stress, J. Geophys. Res., 100, $18205-$ $18228,1995$.

Dahlen, F. A., The balance of energy in earthquake faulting, Geophys. J. R. astr. Soc., 48, 239-261, 1977.

Dieterich, J. H., Modeling of rock friction 1. Experimental results and constitutive equations, J. Geophys. Res., 84, 2161-2168, 1979a.

Dieterich, J. H., Modeling of rock friction 2. Simulation of preseismic slip, J. Geophys. Res., 84, 2169-2175, 1979 b.

Dmowska, R., and J. R. Rice, Fracture theory and Its seismological applications, in Theories in Solid Earth Physics, edited by R. Teisseyre, pp. 187-255, PWN-Polish Publishers, Warzawa, 1986.

Ellsworth, W. L., and G. C. Beroza, Seismic evidence for an earthquake nucleation phase, Science, 268, 851-855, 1995.

Ellsworth, W. L., and G. C. Beroza, Observation of the seismic nucleation phase in the Ridgecrest, California, earthquake sequence, Geophys. Res. Lett., 25, 401-404, 1998.

Eshelby, J. D., The determination of the elastic field of an ellipsoidal inclusion and related problems, Proceedings of the Royal Soc. London, 241, 376-396, 1957.

Eshelby, J. D., The elastic field of a crack extending nonuniformly under general anti-plane loading, J. Mech. Phys. Solids, 17, 177-199, 1969.

Fletcher, J. B., and J. Boatwright, Source parameters of Loma Prieta aftershocks and wave propagation characteristics along the San Francisco peninsula from a joint inversion of digital seismograms, Bull. Seismol. Soc. Am., 81, 17831812, 1991.

Freund, L. B., Dynamic Fracture Mechanics, Cambridge Univ. Press, New York, 1-563, 1998.

Goldsby, D. L., and T. E. Tullis, Experimental observations of frictional weakening during large and rapid slip (abstract), EOS, Transactions, American Geophysical Union, 79, F610, 1998.

Goldsby, D. L., and T. E. Tullis, Dramatic reduction in friction of quartz at rapid but subseismic slip (abstract), Seismological Research Letters, 70, 247, 1999.

Guatteri, M., and P. Spudich, Coseismic temporal changes of slip direction: the effect of absolute stress on dynamic rupture, Bull. Seismol. Soc. Am., 88, 777-789, 1998.

Hall, J. F., T. Heaton, M. W. Halling, and D. J. Wald, Nearsource ground motion and its effects on flexible buildings, Earthquake Spectra, 11, 569-605, 1995.

Hanks, T. C., Earthquake stress drops, ambient tectonic stresses and stresses thatderive plate motions, Pure Appl. Geophys., 115, 441-458, 1977.

Heaton, T., Evidence for and implications of self-healing pulses of slip in earthquake rupture, Physicsof the Earth and Planetary Interiors, 64, 1-20, 1990.

Heaton, T., J. F. Hall, D. J. Wald, and M. W. Halling, 
Response of high-rise and base-isolated buildings to a hypothetical $\mathrm{M}_{\mathrm{w}} 7.0$ blind thrust earthquake, Science, 267, 206-211, 1995.

Hubbert, M. K., and W. W. Rubey, Role of fluid pressure in mechanics of overthrust faulting, Bull. Geol. Soc. Am., 70, 115-166, 1959.

Hull, J., Thickness-displacement relationships for deformation zones, Journal of Structural Geology, 10, 431-435, 1988.

Husseini, M. I., Energy balance for formation along a fault, Geophys. J. R. astr. Soc., 49, 699-714, 1977.

Ide, $S$., and M. Takeo, Determination of constitutive relations of fault slip based on seismic wave analysis, J. Geophys. Res., 102, 27,379-27,391, 1997.

Imamura, A., On the seismic activity of central Japan, Jap. J. Astron. Geophys., 6, 119-137, 1928.

Irwin, W. P., and I. Barnes, Effectof geologic structure and metamorphic fluids on seismic behavior of the San Andreas fault system in central and northern California, Geology, 3, 713-716, 1975.

Ishibashi, K., Specification of a soon-to-occur seismic faulting in the Tokai district, central Japan, based upon seismotectonics, in Earthquake Prediction, An International Review, edited by D. W. Simpson and P. G. Richards, pp. 297-332, American Geophysical Union, Washington, D. C., 1981.

Ishibashi, K., Inferred Tokai earthquake paired with the 1361 Shohei Nankai earthquake (abstract), Programme and Abstracts, The Seismological Society of Japan, 1998, Fall Meeting, PI25, 1998.

Ito, H., H. Naka, D. Lockner, T. Kiguchi, H. Tanaka, R. Ikeda, T. Ohtani, K. Fujimoto, and Y. Kuwahara, Permeability of the Nojima fault: Comparison of borehole results with core measurements (abstract), Programme and Abstracts, The Seismological Society of Japan, 1998, Fall Meeting, B20, 1998.

Jeffreys, H., On the mechanics of faulting, Geol. Mag., 79, 291-295, 1942.

Kanamori, H., Mechanism of tsunami earthquakes, Phys. Earth Planet. Inter., 6, 346-359, 1972.

Kanamori, H., The state of stress in the Earth's lithosphere, in Phys. Earth's Int., Course LXXVIII, edited by A. M. Dziewonski and E. Boschi, pp. 531-554, North-Holland Pub. Co., Amsterdam, 1980.

Kanamori, H., Mechanics of Earthquakes, Ann. Rev. Earth \& Planetary Sciences, 22, 207-237, 1994.

Kanamori, H., and D. L. Anderson, Theoretical basis of some empirical relations in seismology, Bull. Seis. Soc. Amer., $65,1073-1095,1975$.

Kanamori, H., T. H. Anderson, and T. H. Heaton, Frictional melting during the rupture of the 1994 Bolivian Earthquake, Science, 279, 839-842, 1998.

Kanamori, H., E. Hauksson, L. K. Hutton, and L. M. Jones, Determination of Earthquake Energy Release and $\mathrm{M}_{\mathrm{L}}$ Using TERRAscope, Bull. Seismol. Soc. Am., 83, 330-346, 1993.

Kanamori, H., J. Mori, and T. H. Heaton, The 3 December 1988, Pasadena earthquake $\left(M_{L}=4.9\right)$ recorded with the very broadband system in Pasadena, Bull. Seismol. Soc. Am., $80,483-487,1990$

Kikuchi, M., Strain drop and apparent strain for large earthquakes, Tectonophysics, 211, 107-113, 1992.

Kikuchi, M., Size dependence of moment-rate function (abstract), in 1997 IASPEI meeting, Thesaloniki, Greece, 1997.

Kikuchi, M., and Y. Fukao, Seismic wave energy inferred from long-period body wave inversion, Bull. Seismol. Soc. Am., 78, 1707-1724, 1988.

Knopoff, L., Energy release in earthquakes, Geophysic. Jour., I, 44-52, 1958.

Kostrov, B. V., Unsteady propagation of longitudinal shear cracks, J. Appl. Math. Mech. (transl. P. M. M.), 30, 1241 1248, 1966.

Kostrov, B. V., Seismic moment and energy of earthquakes, and seismic flow of rock (translated to English), Izv. Earth Physics, 1, 23-40, 1974.

Kostrov, B. V., and S. Das, Principles of Earthquake Source Dynamics, Cambridge University Press, Cambridge, 1-286, 1988.

Lachenbruch, A. H., Frictional heating, fluid pressure, and the resistance to fault motion, J. Geophys. Res., 85, 6097$6112,1980$.

Lachenbruch, A. H., and J. H. Sass, Heat flow and energetics of the San Andreas fault zone, J. Geophys. Res., 85, 61856222, 1980.

Lawn, B., Fracture of Brittle Solids - Second Edition, Cambridge University Press, Cambridge, 1-378, 1993.

Li, Y. G., K. Aki, D. Adams, A. Hasemi, and W. H. K. Lee, Seismic guided waves trapped in the fault zone of the Landers, California, earthquake of 1992, J. Geophys. Res., 99, 11,705-11,722, 1994.

Li, Y. G., K. Aki, and F. L. Vernon, San Jacinto fault zone guided waves: A discrimination for recently active fault strands near Anza, California, J. Geophys. Res., 102, 11,689-11,701, 1997.

Lin, A., Glassy pseudotachylyte veins from the Fuyun fault zone, northwest China, Journal of Structural Geology, 16, 71-83, 1994a.

Lin, A., Microlite morphology and chemistry in pseudotachylyte from the Fuyun fault zone, China, Journal of Geology, 102, 317-329, $1994 \mathrm{~b}$.

Lin, A., Injection veins of crushing-originated pseudotachylyte and fault gouge formed during seismic faulting, Engineering Geology, 43, 213-224, 1996.

Lin, A., T. Matsuda, and T. Shimamoto, Pseudotachylyte from the Iida-Matsukawa fault, Nagano prefecture: Pseudotachylyte of crush origin? (in Japanese), Kozo Chishitsu (Structural Geology), 39, 51-64, 1994.

Mase, C. W., and L. Smith, Pore-fluid pressures and frictional heating on a fault surface, Pure and Applied Geophysics, 122, 583-607, 1985.

Mase, C. W., and L. Smith, Effects of frictional heating on the thermal, hydrologic, and mechanical response of a fault, $J$. Geophys. Res., 92, 6249-6272, 1987.

Mayeda, K., and W. R. Walter, Moment, energy, stress drop, and source spectra of western United States earthquakes from regional coda envelopes, J. Geophys. Res., 101, 11,195$11.208,1996$.

McGarr, A., Some constraints on levels of shear stress in the crust from observations and theory, J. Geophys. Res., 85, $6,231-6238 ; 1980$. 
McGarr, A., On relating apparent stress to the stress causing earthquake fault slip, J. Geophys. Res., 104, 3,003-3,011, 1999.

McKenzie, D. P., and J. N. Brune, Melting on fault planes during large earthquakes, Geophys. J. R. astr. Soc., 29, 6578, 1972.

Melosh, J., Acoustic fluidization: a new geologic process?, $J$. Geophys. Res., 84, 7513-7520, 1979.

Melosh, H. J., Dynamical weakening of faults by acoustic fluidization, Nature, 379, 601-606, 1996.

Mikumo, T., and T. Miyatake, Dynamic rupture processes on a dipping fault, and estimates of stress drop and strength excess from the results of waveform inversion, Geophys. J. Int., 112, 481-496, 1993.

Miyatake, T., Dynamic rupture process of inland earthquakes in Japan: Weak ad strong asperities, Geophys. Res. Lett., 19, 1041-1044, 1992a.

Miyatake, T., Reconstruction of dynamic rupture process of an earthquake with constraints of kinematic parameters, Geophys. Res. Lett., 19, 349-352, 1992 b.

Mora, P., and D. Place, Numerical simulation of of earthquake faults with gauge: Towards a comprehensive explanation for the heat flow paradox, J. Geophys. Res., 103, 21,06721,089, 1998.

Mora, P., and D. Place, The weakness of earthquake faults, Geophys. Res. Lett., 26, 123-126, 1999.

Mori, J., H. Kanamori, J. Davis, E. Hauksson, R. Clayton, T. Heaton, L. Jones, and A. Shakal, Major improvements in progress for southern California earthquake monitoring, EOS Trans. American Geophysical Union, 79, 217-221, 1998.

Morrow, C. A., and J. D. Byerlee, Permeability of core samples from Cajon Pass scientific drill hole: Results from 2100 to $3500 \mathrm{~m}$ depth, J. Geophys. Res., 97, 5145-5151, 1992.

Mount, V., and J. Suppe, State of stress near the San Andreas fault: Implications for wrench tectonics, Geology, 15, 1143-1146, 1987.

Nadeau, R. M., and L. R. Johnson, Seismological studies at Parkfield VI: Moment release rates and estimates of source parameters for small repeating earthquakes, Bull. Seismol. Soc. Am., 88, 790-814, 1998.

Obata, M., and S. Karato, Ultramafic pseudotachylite from the Balmuccia peridotite, Ivrea-Verbano zone, northern Italy, Tectonophysics, 242, 313-328, 1995.

Okubo, P. G., and K. Aki, Fractal geometry in the San Andreas fault system, J. Geophys. Res., 92, 345-355, 1987.

Orowan, E., Mechanism of seismic faulting in rock deformation, Geol. Soc. Am. Mem., 79, 323-345, 1960.

Otsuki, K., On the relationship between the width of shear zone and the displacement along fault, Jour. of Geolog. Soc. Japan, 84, 661-669, 1978.

Otsuki, K., Physical process of seismic frictional sliding observed in samples from fault zones (translated from Japanese), Chikyu Monthly, 213-224, 1998.

Quin, H., Dynamic stress drop and rupture dynamics of the October 15, 1979 Imperial Valley, California, earthquake, Tectonophysics, 175, 93-117, 1990.

Richards, P. G., Dynamic motions near an earthquake fault: a three-dimensional solution, Bull. Seismol. Soc. Am., 66, 1$32,1976$.
Rice, J. R., Fault stress states, pore pressure distributions, and the weakness of the San Andreas fault, in Fault Mechanics and Transport Properties of Rocks: A Festschrift in Honor of W. F. Brace, edited by B. Evans and W. Teng-fong, pp. 475-503, Academic Press, New York, 1992.

Ruff, L., and H. Kanamori, Seismic coupling and uncoupling at subduction zones, Tectonophysics, 99, 99-117, 1983.

Savage, J. C., and J. B. Walsh, Gravitational energy and faulting, Bull. Seismol. Soc. Am., 68, 1613-1622, 1978.

Savage, J. C., and M. D. Wood, The relation between apparent stress and stress drop, Bull. Seismol. Soc. Am., 61, 13811388, 1971.

Schallamach, A., How does rubber slide?, Wear, 17, 301-312, 1971.

Scholz, C. H., Shear heating and the state of stress on faults, $J$. Geophys. Res., 85, 6174-6184, 1980.

Scholz, C. H., The mechanics of earthquake faulting, Cambridge University Press, New York, 1-438, 1990.

Scholz, C. H., and C. Aviles, The fractal geometry of faults and faulting, in Earthquake Source Mechanics, AGU Geophys. Mono. 37, edited by S. Das, J. Boatwright and C. Scholz, pp. 147-155, American Geophysical Union, Washington, D. C., 1986.

Scholz, C., and J. Campos, On the mechanism of seismic decoupling and back-arc spreading at subduction zones, $J$. Geophys . Res., 100, 22103-22115, 1995.

Scott, D. R., Seismicity and stress rotation in a granular model of the brittle crust, Nature, 381, 592-595, 1996.

Sibson, R. H., Interactions between temperature and fluid pressure during earthquake faulting -- A mechanism for partial or total stress relief, Nature, 243, 66-68, 1973.

Sibson, R. H., Generation of pseudotachylite by ancient seismic faulting, Geophys. J. R. astr. Soc., 43, 775-794, 1975.

Sibson, R. H., Kinetic shear resistance, fluid pressures and radiation efficiency during seismic faulting, Pure and Applied Geophysics, 115, 387-400, 1977.

Sibson, R. H., Power dissipation and stress levels on faults in the upper crust, J. Geophys. Res., 85, 6239-6247, 1980.

Sieh, K., Lateral offsets and revised dates of large prehistoric earthquakes at Pallett Creek, southern California, $J$. Geophys. Res., 89, 7641-7670, 1984.

Singh, S. K., and M. Ordaz, Seismic energy release in Mexican subduction zone earthquakes, Bull. Seismol. Soc. Am., 84, 1533-1550, 1994.

Spray, J. G., Viscosity determinations of some frictionally generated silicate melts - Implications for fault zone rheology at high-strain rates, J. Geophys. Res., 98, 80538068, 1993.

Spudich, P. K. P., On the inference of absolute stress levels from seismic radiation, Tectonophysics, 211, 99-106, 1992.

Spudich, P., M. Guatteri, K. Otsuki, and J. Minagawa, Use of fault striations and dislocation models to infer tectonic shear stress during the 1995 Hyogo-ken Nanbu (Kobe) earthquake, Bull. Seismol. Soc. Am., 88, 413-427, 1998.

Thatcher, W., and T. Hanks, Source parameters of southern California earthquakes, J. Geophys. Res., 78, 8547-8576, 1973.

Thio, H. K., 1 - Using Short-Period Surface Waves to Study 
Seismic Source and Structure. 2 - Source Complexity of Large Strike-Slip Earthquakes, Ph.D thesis, pp., California Institute of Technology, 1996.

Tsutsumi, A., and T. Shimamoto, High-velocity frictional properties of gabbro, Geophys. Res. Lett., 24, 699-702, 1997.

Tullis, T. E., and D. L. Goldsby, Laboratory experiments on rock friction focussed on understanding earthquake mechanics, USGS Technical Report, Vol. 40, http://erpweb.er.usgs.gov/reports/VOL40/pt/g3034.htm, 1998.

Umeda, Y., High-amplitude seismic waves radiated from the bright spot of an earthquake, Tectonophysics, 141, 335$343,1990$.

Umeda, Y., The bright spot of an earthquake, Tectonophysics, $211,13-22,1992$.

Uyeda, S., and H. Kanamori, Back-arc opening and the mode of subduction, J. Geophys. Res., 84, 1049-1061, 1979.

Wald, D. J., Strong motion and broadband teleseismic analysis of the 1991 Sierra Madre, California, earthquake, $J$. Geophys. Res., 97, 11,033-11,046, 1992.

Weertman, J., Unstable slippage across a fault that separates elastic media of different elastic constants, J. Geophys. Res., 85, 1455-1461, 1980.

Wesnousky, S. G., The Gutenberg-Richter or Characteristic Earthquake Distribution, Which is it?, Bull. Seismol. Soc. Am., 84, 1940-1959, 1994.

Winslow, N., and L. Ruff, A hybrid method for calculating the radiated wave energy of deep earthquakes, Physics of the Earth and Planetary Interiors, 115, 181-190, 1999.

Wyss, M., Apparent stress of earthquakes on ridges compares to apparent stresses of earthquakes in trenches, Geophys. $J$. R. astr. Soc., 19, 479-484, 1970a.
Wyss, M., Stress estimates for south American shallow and deep earthquakes, J. Geophys. Res., 75, 1529-1544, 1970b.

Wyss, M., and J. N. Brune, Seismic moment, stress, and source dimensions for earthquakes in the California-Nevada region, J. Geophys. Res., 73, 4681-4694, 1968.

Yamashita, T., Simulation of seismicity due to fluid migration in a fault zone, Geophys. J. Int., 132, 674-686, 1998.

Zhu, L., Broadband Waveform Modeling and Its Application to the Lithospheric Structure of the Tibetan Plateau, Ph.D thesis, pp., California Institute of Technology, 1998.

Zoback, M. D., and G. C. Beroza, Evidence for nearfrictionless faulting in the 1989 (M 6.9) Loma Prieta, California, earthquake and its aftershocks, Geology, 2l, 181-185, 1993.

Zoback, M., and A. H. Lachenbruch, Introduction to the special section on the Cajon Pass scientific drilling project, $J$. Geophys. Res., 97, 4991-4994, 1992.

Zoback, M. D., M. L. Zoback, V. S. Mount, J. Suppe, J. Eaton, D. Healy, P. Oppenheimer, L. Reasenberg, L. Jones, B. Raleigh, 1. Wong, O. Scotti, and C. Wentworth, New evidence on the state of stress of the San Andreas fault system, Science, 238, 1105-1111, 1987.

Hiroo Kanamori, Seismological Laboratory, California Institute of Technology, Pasadena, California 91125, (626) 395-6914, FAX 626-564-0715, hiroo@gps.caltech.edu.

Thomas H. Heaton, Seismological Laboratory, California Institute of Technology, Pasadena, CA 91125, (626) 6897, FAX 626-564-0715, heaton@gps.caltech.edu. 